\title{
National Cholesterol Education Program: Highlights of the Report of the Expert Panel* on Blood Cholesterol Levels in Children and Adolescents
}

\author{
US DEPARTMENT OF HEALTH AND HUMAN SERVICES \\ PUBLIC HEALTH SERVICE \\ NATIONAL INSTITUTES OF HEALTH \\ NATIONAL HEART, LUNG, AND BLOOD INSTITUTE
}

Compelling evidence exists that the atherosclerotic process begins in childhood and progresses slowly into adulthood, at which time it leads frequently to coronary heart disease (CHD), the major cause of death in the United States. Despite substantial success in reducing CHD mortality in the past two decades, the disease is still responsible for more than 500,000 deaths annually. About 20 percent of hospital discharges for acute CHD are for premature disease, i.e., in patients under 55 years of age. Many of these adults have children who may have CHD risk factors that need attention. Estimates of the annual cost of CHD range from $\$ 41.5$ to $\$ 56$ billion.

\footnotetext{
*Members: Ronald M. Lauer, MD, Chairman of the Panel; Lewis A. Barness, MD; Rene Clark, RN, EdD; Richard J. Deckelbaum, MD; Laurence Finberg, MD; Peter O. Kwiterovich, Jr, MD; Patrick E. McBride, MD, MPH; Richard M. Schieken, MD, FACC; Lynne W. Scott, MA, RD, LD; Jack P. Strong, MD; William H. Weidman, MD; Ekhard E. Ziegler, MD. Ex-Officio members: James I. Cleeman, MD, Coordinator, National Cholesterol Education Program; Nancy Ernst, MS, RD; William R. Harlan, MD; Basil Rifkind, MD; Jacques E. Rossouw, MD. Staff: Laurie Quint-Adler, MPH, RD; Caroline T. McNeil, MLS. Acknowledgment: The panel would like to thank Karen Donato, MS, RD, and Marguerite Evans, MS, RD, of the National Heart, Lung, and Blood Institute for their assistance in the preparation of this report.
}

The Report of the Expert Panel on Blood Cholesterol Levels in Children and Adolescents ${ }^{\dagger} \mathrm{re}-$ views the evidence that atherosclerosis or its precursors begin in young people; that elevated cholesterol levels early in life play a role in the development of adult atherosclerosis; that eating patterns and genetics affect blood cholesterol levels and CHD risk; and that lowering levels in children and adolescents will be beneficial. Cholesterol is the focus of the report, but other risk factors for atherosclerosis and CHD may originate early in life and should be addressed as well. Specifically, cigarette smoking should be discouraged; hypertension should be identified and treated; obesity should be avoided or reduced; regular aerobic exercise should be encouraged; and diabetes mellitus should be diagnosed and treated.

\section{The significance of blood cholesterol levels in childhood and adolescence} The mean blood total cholesterol level of American children and adolescents is roughly 160 $\mathrm{mg} / \mathrm{dL}$; the mean LDL-cholesterol level is about $100 \mathrm{mg} / \mathrm{dL}$. From 1 to 19 years of age,

†Copies of the report and the highlights are available from: National Cholesterol Education Program, NHLBI Information Center, P.O. Box 50105 Bethesda, MD 208240105 . 
the 75 th percentile for total cholesterol is roughly $170 \mathrm{mg} / \mathrm{dL}$, and for LDL-cholesterol about $110 \mathrm{mg} / \mathrm{dL}$. The $95 \mathrm{th}$ percentile for total cholesterol is roughly $200 \mathrm{mg} / \mathrm{dL}$, and for LDLcholesterol about $130 \mathrm{mg} / \mathrm{dL}$.

High blood cholesterol levels clearly play a role in the development of CHD in adults. This has been established by many laboratory, clinical, pathological, and epidemiologic studies. A variety of studies also have demonstrated that the atherosclerotic process begins in childhood and is affected by high blood cholesterol levels. The evidence can be summarized as follows:

- Compared to their counterparts in many other countries, U.S. children and adolescents have higher blood cholesterol levels and higher intakes of saturated fatty acids and cholesterol, and U.S. adults have higher blood cholesterol levels and higher rates of CHD morbidity and mortality.

- Autopsy studies demonstrate that early coronary atherosclerosis or precursors of atherosclerosis often begin in childhood and adolescence.

- High serum total cholesterol, LDL-cholesterol, and VLDL-cholesterol levels, and low HDL-cholesterol levels, are correlated with the extent of early atherosclerotic lesions in adolescents and young adults.

- Children and adolescents with elevated serum cholesterol, particularly LDL-cholesterol levels, frequently come from families in which there is a high incidence of CHD among adults members.

- High blood cholesterol aggregates in families as a result of both shared environments and genetic factors.

- Children and adolescents with high cholesterol levels are more likely than the general population to have high levels as adults.

To lower blood cholesterol levels in children and adolescents, the panel recommends a strategy that combines two complementary approaches: a) a population approach and b) an individualized approach.

\section{The population approach}

The population approach, which serves as the principal means for preventing $\mathrm{CHD}$, aims to lower the average levels of blood cholesterol among all American children and adolescents through population-wide changes in nutrient intake and eating patterns. An advantage of this approach is that even a relatively small reduction of mean total and LDL-cholesterol levels in childhood and adolescence, if carried into adulthood, could substantially decrease the incidence of CHD. It can also improve nutrition in general and help prevent a variety of chronic conditions and diseases. This panel's population recommendations are congruent with those issued by the National Cholesterol Education Program (NCEP) Expert Panel on Population Strategies for Blood Cholesterol Reduction, the Dietary Guidelines for Americans, the U.S. Surgeon General, the National Research Council, the American Heart Association, and the National Cancer Institute.

The following nutrient recommendations are intended for all healthy children and adolescents over the age of about 2 years:

- Nutritional adequacy should be achieved by eating a wide variety of foods.

- Energy (calories) should be adequate to support growth and development and to reach or maintain desirable body weight.

- The following pattern of nutrient intake is recommended:

- Saturated fatty acids-less than 10 percent of total calories

- Total fat-an average of no more than 30 percent of total calories

-Dietary cholesterol-less than $300 \mathrm{mg}$ per day.

Each of these recommendations is intended to refer to an average of nutrient.intake over a period of several days. Table 1 shows a comparison of the current versus recommended nutrient intake in American children and adolescents.

To achieve the recommended nutrient intake, the panel recommends an eating pattern in which families select, prepare, and consume foods low in saturated fatty acids, total fat, and cholesterol; choose a variety of foods to ensure adequate intake of carbohydrates, protein, and other nutrients; and consume only enough calories to maintain desirable weight. This eating pattern supports normal growth and develop- 
ment; it provides enough total energy and meets or exceeds the recommended dietary allowances for all nutrients for children and adolescents, including iron and calcium.

The panel's recommendations are not intended for infants from birth to 2 years of age, whose fast growth requires a higher percentage of calories from fat. Toddlers 2 and 3 years of age may safely make the transition to the recommended eating pattern as they begin to eat with the family.

The panel also directs recommendations to groups that influence the eating patterns of children and adolescents.

- Schools, through breakfast and lunch programs, should increase the availability and encourage the selection of foods that are both appealing to young people and low in saturated fatty acids, total fat, and cholesterol. Because some children, including those from lower socioeconomic groups, may obtain a substantial portion of their calories from school meal programs, care must be taken to ensure that adequate amounts of nutrients are supplied when saturated fatty acids, total fat, and cholesterol are reduced. Schools should also incorporate into their curricula information about healthful eating patterns and CHD prevention at all grade levels from preschool through high school. Understanding and use of food labels should be taught as a part of the curricula.

- Health professionals, including physicians, nurses and nurse practitioners, registered dietitians and other qualified nutrition professionals, health educators, pharmacists, and others can promote the recommended eating patterns in various ways. Nutrition education should be a routine part of well-child care. In addition, health professionals can serve as resources to their communities in developing nutrition education and $\mathrm{CHD}$ risk reduction programs.

- Government agencies should provide more nutrition education and continue the development of regulations to improve food labeling. Food assistance programs, such as school lunch programs, should expand the availability and encourage the selection of foods appealing to children that are low in saturated fatty acids, total fat, and cholesterol. Agencies should also continue collaboration among themselves and with voluntary organizations to provide more consistent nutrition statements.

- The food industry should increase efforts to design, modify, prepare, promote, label, and distribute foods low in saturated fatty acids, total fat, and cholesterol that are good tasting, safe, and appealing to children.

- The mass media, through their news, educational, and entertainment programming, should provide information on a lower saturated fatty acid, lower total fat, and lower cholesterol eating pattern for children and adolescents.

\section{The individualized approach}

The individualized approach to cholesterol lowering, which calls for the cooperative effort of the entire health professional team, aims to identify and treat children and adolescents who are at the greatest risk of having high blood cholesterol as adults and an increased risk of CHD. The panel sought ways to identify individual children and adolescents whose elevated cholesterol levels are likely to signify such increased risk.

\section{Selective screening}

The panel recommends selectively screening, in the context of regular health care, children and adolescents who have a family history of premature cardiovascular disease (CVD) or at least one parent with high blood cholesterol. The panel focused on these young people because of strong evidence demonstrating a familial aggregation of CHD, high blood cholesterol, and other risk factors (shown in Table 2).

Before recommending this selective screening approach, the panel carefully considered the advantages and disadvantages of universal screening, that is, the screening of all children and adolescents in the United States. While universal screening would make it possible to identify all those with high cholesterol levels, it has significant drawbacks. The panel decided not to recommend universal screening for the following reasons: 1) Although high cholesterol levels in childhood generally pre- 


\begin{tabular}{|c|c|c|}
\hline \multicolumn{3}{|c|}{$\begin{array}{c}\text { Table 1 } \\
\text { Current Versus Recommended } \\
\text { Nutrient Intake in Children } \\
\text { and Adolescents }\end{array}$} \\
\hline & Current* & Recommended \\
\hline $\begin{array}{l}\text { Saturated fatty } \\
\text { acids }\end{array}$ & $14 \%$ calories & $<10 \%$ calories \\
\hline Total fat & $35 \%-36 \%$ & $\begin{array}{l}\text { Average no } \\
\text { more than } \\
30 \%\end{array}$ \\
\hline Polyunsaturated & $6 \%$ & Up to $10 \%$ \\
\hline Monounsaturated & $13 \%-14 \%$ & $10 \%-15 \%$ \\
\hline Cholesterol & $\begin{array}{r}193-296 \\
\mathrm{mg} / \text { day }\end{array}$ & $<300 \mathrm{mg} /$ day \\
\hline $\begin{array}{l}\text { *Source: Preliminary dat: } \\
\text { Food Consumption Survey. }\end{array}$ & a from USDA's 1 & 987-1988 Nationwide \\
\hline
\end{tabular}

Table 2

Other Risk Factors That May Contribute to Earlier Onset of Coronary Heart Disease (CHD)

- Family history of premature CHD, cerebrovascular or occlusive peripheral vascular disease (definite onset before the age of 55 years in a sibling, parent, or sibling of a parent)

- Cigarette smoking

- Elevated blood pressure

- Low HDL-cholesterol concentration $(<35 \mathrm{mg} / \mathrm{dL})$

- Severe obesity $(\geqslant 95$ th percentile weight for height by National Center for Health Statistics growth charts)*

- Diabetes mellitus

- Physical inactivity

*This corresponds to $\geqslant 30 \%$ overweight.

dict cholesterol elevations in adulthood, quite a few children with high cholesterol levels will not have high enough levels as adults to qualify for individualized treatment. 2) Universal screening could lead to the labeling of many young people as patients with a "disease," causing unjustified anxiety for them and their families. 3) For most children not from high-risk families, there is sufficient opportunity to begin cholesterol-lowering therapies when they reach adulthood. 4) There is insufficient evidence concerning the long-term safety and the efficacy of drug therapy in children to reduce CHD morbidity and mortality in adulthood;
Table 3

Classification of Total and LDL-Cholesterol

Levels in Children and Adolescents From

Families With Hypercholesterolemia or Premature Cardiovascular Disease

\begin{tabular}{|lcc|}
\hline Category & $\begin{array}{c}\text { Total } \\
\text { cholesterol } \\
(\mathbf{m g} / \mathbf{d L})\end{array}$ & $\begin{array}{c}\text { LDL- } \\
\text { cholesterol } \\
(\mathbf{m g} / \mathbf{d L})\end{array}$ \\
\hline Acceptable & $<170$ & $<110$ \\
Borderline & $170-199$ & $110-129$ \\
High & $\geqslant 200$ & $\geqslant 130$ \\
\hline
\end{tabular}

universal screening could lead to overuse of cholesterol-lowering drugs in childhood and adolescence.

Although it did not recommend universal screening, the panel agreed that for a certain subset of children and adolescents at highest risk, i.e., those with a family history of premature CVD or parental hypercholesterolemia, it is prudent to initiate individual treatment at an early age. The selective screening approach recommended by the panel makes it possible to identify this subset while providing a reasonable balance between the number to be tested and the number to be detected.

The panel makes the following specific recommendations for selective screening of children and adolescents in the context of their continuing health care.

- Screen children and adolescents whose parents or grandparents, at 55 years of age or less, underwent diagnostic coronary arteriography and were found to have coronary atherosclerosis. This includes parents or grandparents who have undergone balloon angioplasty or coronary artery bypass surgery. The panel believes that adult cardiologists should make a routine practice of referring the offspring of these patients to a source of continuing health care for cholesterol testing and followup.

- Screen children and adolescents whose parents or grandparents, at 55 years of age or less, suffered a documented myocardial infarction, angina pectoris, peripheral vascular disease, cerebrovascular disease, or sud- 


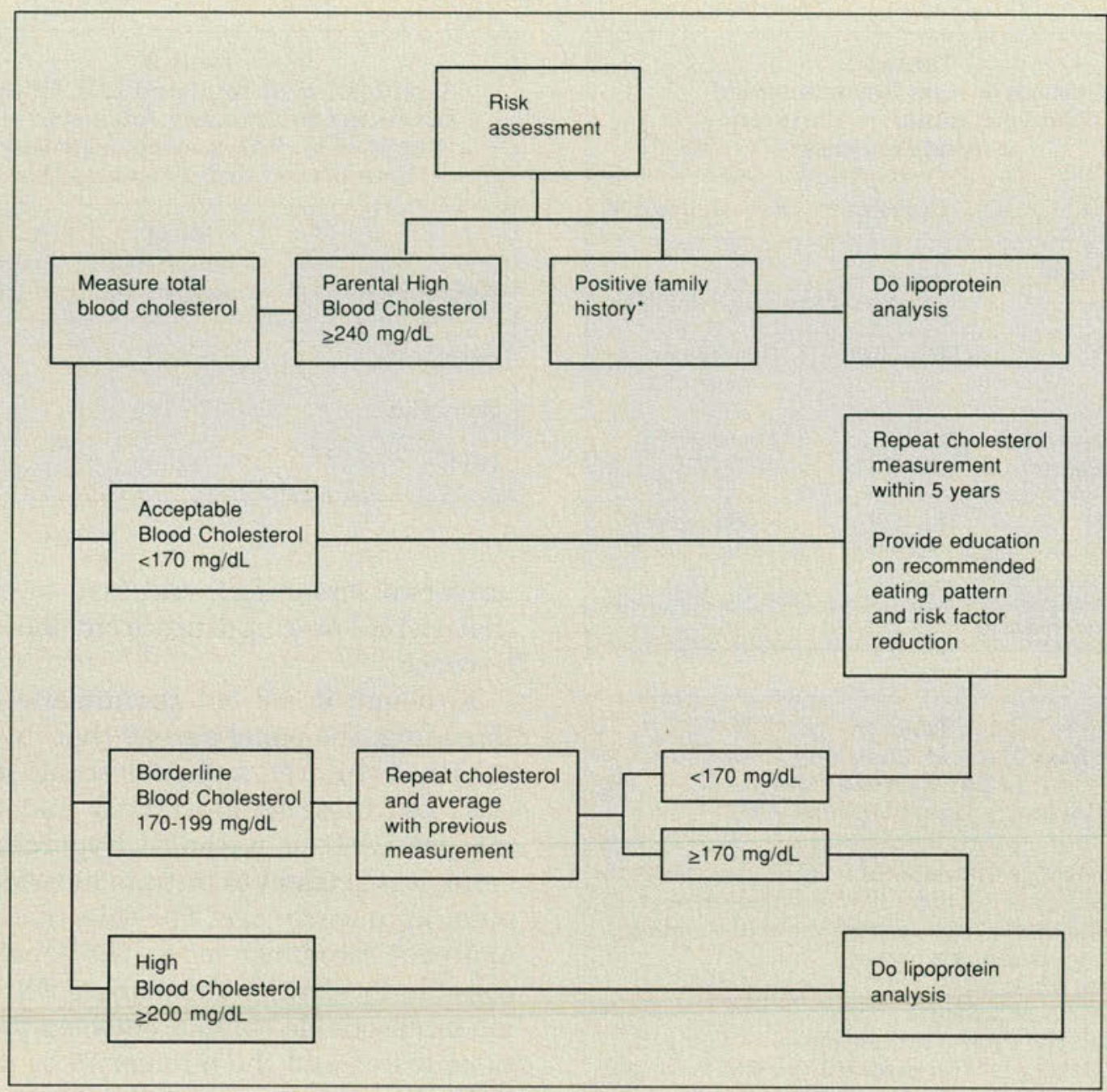

Figure 1. Risk assessment. * Defined as a history of premature (before age 55 years) cardiovascular disease in a parent or grandparent.

den cardiac death. Adult cardiologists should also make a routine practice of referring the offspring of these patients to a source of continuing health care for cholesterol testing and followup.

- Screen the offspring of a parent who has been found to have high blood cholesterol (240 $\mathrm{mg} / \mathrm{dL}$ or higher).

- For children and adolescents whose parental or grandparental history is unobtainable, particularly those with other risk factors, physicians ${ }^{1}$ may choose to measure cholesterol

\footnotetext{
${ }^{1}$ In settings where health care practitioners other than physicians are responsible for primary health care of the child, the recommendations pertaining to selective screening are intended to apply to these health care practitioners as well.
}

levels in order to identify those in need of individual nutritional and medical advice.

The National Cholesterol Education Program has recommended that all adults ages 20 and over have their cholesterol measured. Thus an increasing number of parents can be expected to know their cholesterol levels. Screening children and adolescents in the context of continuing health care provides an opportunity for all first-degree family members to have their CVD risk assessed. This opportunity should be provided. The physician caring for the child should arrange for or conduct screening of the parents; parents' siblings may also be included.

Optional cholesterol testing by the practicing physician may be appropriate in certain 


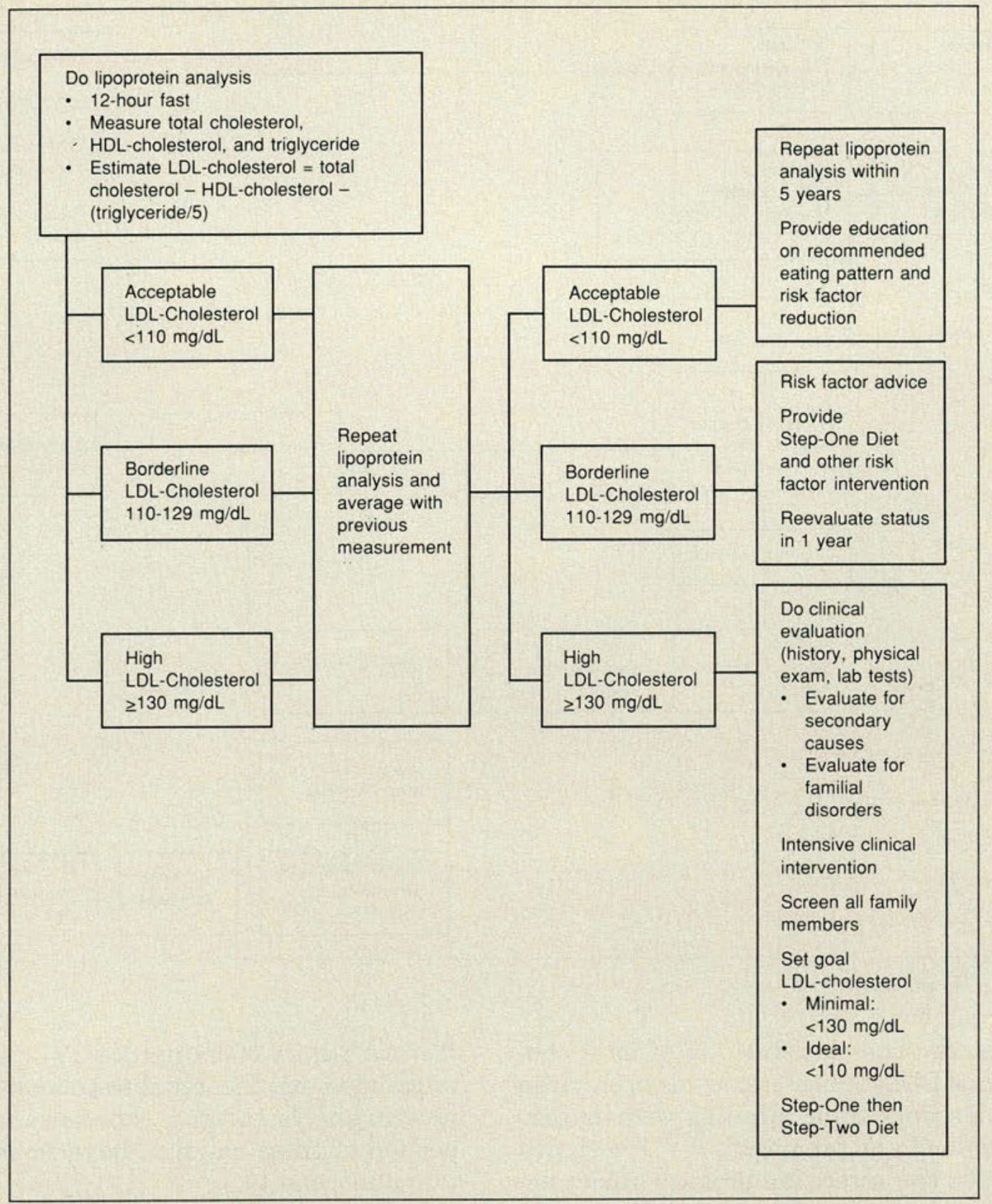

Figure 2. Classification, education, and followup based on LDL-cholesterol.

children who are judged to be at higher risk for CHD independent of family history or parental hypercholesterolemia. For example, adolescents who smoke cigarettes, have high blood pressure, or consume excessive amounts of saturated fatty acids, total fat, and cholesterol, and who are overweight may also deserve cholesterol testing at the discretion of their physician. In cases where the cholesterol level is tested for these and other reasons and an ele- vated cholesterol level is found, the physician should obtain an accurate family history and ascertain the blood cholesterol status of the parents in order to help decide whether individualized treatment of the child or adolescent is appropriate.

The focus of the individualized approach is to detect and treat the hypercholesterolemic child or adolescent whose elevated LDL-cholesterol level is likely to signify increased risk 


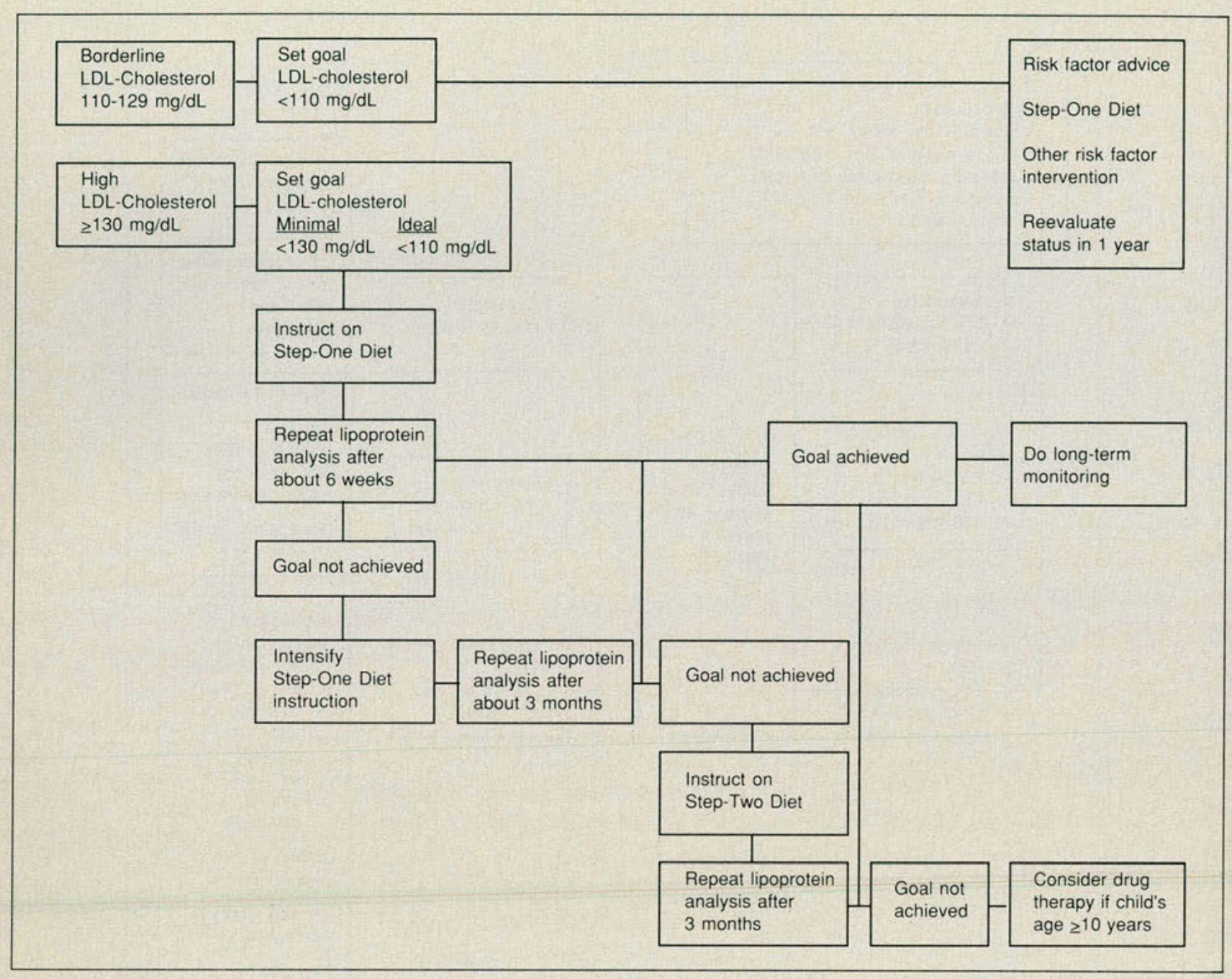

Figure 3. Diet therapy.

in adulthood. The classification of total cholesterol and LDL-cholesterol levels in children and adolescents from families with hypercholesterolemia or premature CVD is shown in Table 3. The screening protocol varies according to the reason for testing. For young people being tested because they have at least one parent with high blood cholesterol, the initial test should be a measurement of total cholesterol. If the child's or adolescent's total cholesterol is high ( $\geq 200 \mathrm{mg} / \mathrm{dL})$, a lipoprotein analysis should be obtained. If the total cholesterol level is borderline $(170-199 \mathrm{mg} /$ $\mathrm{dL})$, a second measurement of total cholesterol should be taken and if the average is borderline or high, a lipoprotein analysis should be obtained (Figure 1).

For young people being tested due to a docu- mented history of premature CVD in a parent or grandparent, the initial test should be a lipoprotein analysis (Figure 1 ) because a high proportion of these children have some lipoprotein abnormality.

In both cases, once a lipoprotein analysis has been obtained, it should be repeated to determine the average LDL-cholesterol level, which will determine the recommended steps for risk assessment and treatment (Figure 2). Followup of the LDL-cholesterol determination is as follows:

\section{- Acceptable LDL-Cholesterol}

$(<110 \mathrm{mg} / \mathrm{dL})$ : If the average LDL-cholesterol is in the acceptable range, provide education on the eating pattern recommended for all children and adolescents and on CHD risk factors; repeat lipoprotein analysis in 5 years. 


\begin{tabular}{|c|c|c|}
\hline \multicolumn{3}{|c|}{$\begin{array}{c}\text { Table 4 } \\
\text { Characteristics of Step-One and Step-Two } \\
\text { Diets for Lowering Blood Cholesterol }\end{array}$} \\
\hline \multirow[b]{2}{*}{ Nutrient } & \multicolumn{2}{|c|}{ Recommended intake } \\
\hline & Step-one diet & Step-two diet \\
\hline Total fat & $\begin{array}{c}\text { Average of no more than } \\
30 \% \text { of total calories }\end{array}$ & Same \\
\hline $\begin{array}{l}\text { Saturated fatty } \\
\text { acids }\end{array}$ & $\begin{array}{l}\text { Less than } 10 \% \text { of total } \\
\text { calories }\end{array}$ & $\begin{array}{l}\text { Less than } 7 \% \text { of } \\
\text { total calories }\end{array}$ \\
\hline $\begin{array}{l}\text { Polyunsaturated } \\
\text { fatty acids }\end{array}$ & Up to $10 \%$ of total calories & Same \\
\hline $\begin{array}{l}\text { Monounsaturated } \\
\text { fatty acids }\end{array}$ & $\begin{array}{l}\text { Remaining total fat } \\
\text { calories }\end{array}$ & Same \\
\hline Cholesterol & Less than $300 \mathrm{mg} /$ day & $\begin{array}{l}\text { Less than } 200 \\
\text { mg/day }\end{array}$ \\
\hline Carbohydrates & About $55 \%$ of total calories & Same \\
\hline Protein & $\begin{array}{l}\text { About } 15 \%-20 \% \text { of total } \\
\text { calories }\end{array}$ & Same \\
\hline Calories & $\begin{array}{l}\text { To promote normal } \\
\text { growth and development } \\
\text { and to reach or maintain } \\
\text { desirable body weight }\end{array}$ & Same \\
\hline
\end{tabular}

\section{- Borderline LDL-Cholesterol}

$(110-129 \mathrm{mg} / \mathrm{dL}$ ): If the average LDL-cholesterol is borderline, provide risk factor advice; initiate the Step-One Diet (see below) and other risk factor intervention; and reevaluate the patient's status in 1 year.

\section{- High LDL-Cholesterol}

$(\geq 130 \mathrm{mg} / \mathrm{dL})$ : If the average LDL-cholesterol level is high, evaluate the patient for secondary causes and familial disorders; screen all family members; and initiate the Step-One Diet, followed if necessary by the Step-Two Diet (Figure 3).

\section{Diet therapy}

Diet therapy is the primary approach to treating children and adolescents with elevated blood cholesterol. The goals of diet therapy are as follows:

- For borderline LDL-cholesterol:

- to lower the level to $<110 \mathrm{mg} / \mathrm{dL}$;

- For high LDL-cholesterol:

- to lower the level to $<130 \mathrm{mg} / \mathrm{dL}$ as a minimal goal;

-to lower the level to $<110 \mathrm{mg} / \mathrm{dL}$ as an ideal goal.

Diet therapy is prescribed in two steps that progressively reduce the saturated fatty acid and cholesterol intake. The Step-One Diet calls for the same nutrient intake recommended in the population approach to lowering cholesterol, i.e., less than 10 percent of total calories from saturated fatty acids; no more than 30 percent of calories from total fat; less than 300 $\mathrm{mg}$ a day of cholesterol; and adequate energy (calories) to support growth and development and to reach or maintain desirable body weight (Table 4). What makes the diet therapeutic is prescription in a medical setting together with the monitoring and followup offered by health professionals. Instruction on the Step-One Diet requires detailed assessment of current eating patterns and instruction by a physician, registered dietitian or other qualified nutrition professional, or other appropriately trained health professional.

If careful adherence to this diet for at least 3 months fails to achieve the minimal goals of therapy, the Step-Two Diet should be prescribed (Figure 3 ). This entails further reduction of the saturated fatty acid intake to less than 7 percent of calories, and of the cholesterol intake to less than $200 \mathrm{mg}$ a day (Table 4). Adoption of the Step-Two Diet requires careful planning to ensure adequacy of nutrients, vitamins, and minerals; a registered dietitian 
or other qualified nutrition professional should be consulted at this stage, if this has not been done before.

\section{Drug therapy}

The panel recommends considering drug therapy in children ages 10 years and older if, after an adequate trial of diet therapy ( 6 months to 1 year):

- LDL-cholesterol remains $\geq 190 \mathrm{mg} / \mathrm{dL}$; or

- LDL-cholesterol remains $\geq 160 \mathrm{mg} / \mathrm{dL}$ and

-There is a positive family history of premature CVD (before 55 years of age), or

- Two or more other CVD risk factors are present in the child or adolescent after vigorous attempts have been made to control these risk factors (Table 2).

Drugs that are currently used for treatment of hypercholesterolemia and high LDL-cholesterol levels in children and adolescents are the bile acid sequestrants cholestyramine and colestipol, which act by binding bile acids in the intestinal lumen. The bile acid sequestrants have proven efficacy, relative freedom from side effects, and apparent safety when used in children and adolescents.

Nicotinic acid, a water-soluble B vitamin, has been used effectively in adults for many years. Experience with its use in growing children is limited, however, and it must be used cautiously in this age group. Nicotinic acid should be prescribed only after referral to a lipid specialist and if cholesterol-lowering therapy by diet and bile acid sequestrants has not reached its specific goals.

Nicotinic acid, HMG CoA reductase inhibitors, probucol, gemfibrozil, D-thyroxine, paraminosalicylic acid (PAS), and clofibrate are not recommended as routine drugs for use in children and adolescents.

Editor's Note: The Report of the Expert Panel on Blood Cholesterol Levels in Children and Adolescents was approved by the National Cholesterol Education Coordinating Committee. Representing the American Osteopathic Association on the committee is Stephen E. Weis, DO. 
Not only could you be missing out on some valuable talent, you could be breaking the law. The Americans with Disabilities Act requires all employers to make workplaces accessible and to give everyone who's qualified the chance to apply for a job - without discrimination. That could mean overlooking your prejudices and giving someone a chance that's long overdue. Support Easter Seals.

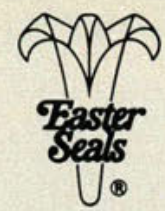

\section{If you overlook thisjobapplicant itcould be a real crime.}

